\title{
Prophylactic Wound Drainage in Orthopaedics: A Comparative Evaluation of Closed Suction Drainage versus No-Drainage in a Nigerian Teaching Hospital
}

\author{
Ikpeme A. Ikpeme ${ }^{1 *}$, Ngim E. Ngim¹, Iniabasi U. Ilori ${ }^{2}$, Enembe Oku ${ }^{3}$, Anthony M. Udosen ${ }^{1}$ \\ ${ }^{1}$ Departments of Orthopaedics \& Traumatology, University of Calabar Teaching Hospital, Calabar, Nigeria \\ ${ }^{2}$ Departments of Anaesthesiology, University of Calabar Teaching Hospital, Calabar, Nigeria \\ ${ }^{3}$ Departments of Community Medicine, University of Calabar Teaching Hospital, Calabar, Nigeria \\ Email: "iaikpeme@yahoo.com
}

Received March 12, 2013; revised April 14, 2013; accepted April 23, 2013

Copyright (C) 2013 Ikpeme A. Ikpeme et al. This is an open access article distributed under the Creative Commons Attribution License, which permits unrestricted use, distribution, and reproduction in any medium, provided the original work is properly cited.

\begin{abstract}
Background: Surgical wound drainage is practiced routinely by many orthopaedic surgeons despite studies that challenge the practice. Among proponents, the advantages of drainage include prevention of haematoma and/or seroma formation which potentially reduces the chances for infection, prevention of wound swelling, prevention of compartment syndrome and improvement of the local wound environment. Opponents argue that prophylactic wound drainage confers no significant advantages, increases the risk of infection and the need for blood transfusion with the attendant risks of this therapy. Aim: To ascertain if prophylactic drainage of clean orthopaedic wounds confer any significant advantages by evaluating wound and systemic factors in two treatment groups. Patients and Methods: A prospective analysis of 62 patients was undergoing clean orthopaedic procedures. The patients were randomly assigned to a "No drain" (study) group and a "drain" (control) group. Each group had 31 patients. Surgeons were blinded to the randomization process and the evaluation of clinical outcomes. The parameters assessed included pain, superficial wound infection, the need for post-operative transfusion, wound leakage, dressing changes and the surgery-discharge interval. Data was analysed using SPSS statistics version 20 (IBM Corp., New York). Results: There were no significant differences in the demographic data. Femoral fractures were the commonest indication for surgery (43.55\%), and plate and screw osteosynthesis was the commonest procedure (48.4\% in the drain group and $67.7 \%$ in the no-drain group). There was a significantly higher need for post-operative transfusion in the drain group (22.6\% against $0 \%)$ as well as a significantly prolonged capillary refill time $(2.39+0.56$ secs versus $2.03+0.41 \mathrm{secs})$. Although not statistically significant, there were four cases $(12.8 \%)$ of superficial wound infection in the drain group and 1 case $(3.2 \%)$ in the no-drain group. Conclusion: Prophylactic wound drainage confers no significant advantages over no drainage and may contribute to increased treatment costs through an increased post-operative transfusion requirements.
\end{abstract}

Keywords: Wound Drain; No-Drain; Complications; Orthopaedics

\section{Introduction}

Surgical drainage has a long history with Hippocrates (400-377BC) credited with the earliest recorded use of drains as a therapeutic technique [1]. Ambrose Pare (1510-1590) is credited with the wide use of drains in Orthopaedics [1,2]. Surgical drains and drainage techniques have evolved over time. Despite studies that challenge the efficacy of prophylactic drainage after clean orthopaedic procedures, prophylactic wound drainage continues to be practiced even with lack of clear evi-

"Corresponding author. dence that they improve outcomes [1,3-5]. The paucity of randomized controlled trials has not helped clinicians arrive at a definitive evidence-based position on the subject $[5,6]$.

The usual documented advantages of prophylactic wound drainage include prevention of haematomas/seromas and hence reduction of the risk of infections, prevention of wound swelling and compartment syndrome, and improvement of the local wound environment which should lead to improved wound healing [1]. The counter argument is that drains may serve as a conduit for organisms and predispose clean wounds to infection. They 
have also been associated with such serious complications as the seeding of malignant neoplasms $[1,2]$. Advancements in operative techniques such as refinements in tissue handling, minimal access techniques, surgical diathermy, lasers and improvements in haemorrhage control contribute to reduction in the volume of devitalized tissue and potential for wound haematomas/seromas. These can potentially reduce the risk for infection. In many developing economies, these advances are rudimentary. This may strengthen the argument for prophylactic wound drainage in these settings. However, the increased potential for wound infection following the use of simple non-suction and open drainage systems are documented [1]. Besides, there is an overall increase in treatment costs when closed suction drainage systems (each costs USD 30 in our environment) are used in these resource-challenged systems. These are strong counter arguments against routine prophylactic drainage of clean wounds even in the developing world.

Despite the long history of orthopaedic wound drainage, opinions differ on the exact risks and benefits of wound drainage [4,7-9]. Besides, there is a paucity of literature from the developing world on randomized studies of Orthopaedic wound drainage. A Cochrane meta-analysis of 36 randomized trials found insufficient evidence to support the routine use of drains in orthopaedic surgery but concluded that there was "a need for further randomized trials particularly for procedures that have not been adequately studied such as fracture and spinal surgery" $[10]$.

\section{Aims and Objectives}

To document wound and systemic factors in two treatment groups and ascertain if prophylactic drainage of clean orthopaedic wounds confer any significant advantage(s). This study provides results of a randomized controlled study from a sub-saharan and resource-challenged setting.

\section{Patients and Methods}

A prospective randomized study was undertaken over 6 months. All patients undergoing clean orthopaedic procedures were randomly assigned to two treatment groups. Those in the study group had no drains inserted in their wounds post- operatively while the patients in the control group had closed suction drainage of their wounds. Surgeons who performed the procedures were blinded to the randomization of patients to the different groups and to the evaluation of clinical outcomes.

Inclusion criteria were clean orthopaedic procedures including osteosynthesis of fresh fractures, arthroplasties and open reduction of old joint dislocations. Malunions and non-unions requiring osteoclasis and osteosynthesis were also included. Exclusion criteria were open fractures, infected malunions and non unions; and surgeries through complicated, unhealthy skin and scars. All patients received prophylactic antibiotics and were offered standard surgical approaches for each indication. Transfusion triggers were agreed upon before the commencement of the study. These were a haemogram of $6 \mathrm{~g} / \mathrm{dl}$ or less associated with a pulse rate of 110 beats per minute or more and a systolic blood pressure of less than 90 mmHg. The patients' general health condition was assessed using the pre-operative Haemoglobin levels, the presence of co-morbid conditions like diabetes mellitus, immunosuppression and hypertensive heart disease as well as a history of smoking.

The parameters assessed in both groups were pain in the first 6 and 12 hours post-operatively (using the $\mathrm{Nu}$ meric scale), swelling, wound leakage, dressing reinforcements or linen changes as well as the clinical features of compartment syndrome within the first 96 hours. Early wound infection, the pre- and post-operative (Day 3) haemoglobin levels and need for transfusion based on previously agreed transfusion triggers, the number of days to suture removal and state of the wounds after removal of sutures (presence or absence of gaping) were also assessed. Ethical committee approval was obtained for this study.

All data were analysed using SPSS Statistic version 20 (IBM Corp., New Castle, New York). Summary data were presented as frequencies, means and standard deviation. Independent group comparison was done using T-test for parametric data and Mann-Whitney U Test for non-parametric data. Categorical data were compared using Pearson's Chi-square, likelihood ratio Chi-square and Fishers Exact test.

\section{Results}

A total of 62 patients were randomized into 2 groups. There were 31 patients each in the study group (No drains) and control group (Drain use). The patients demographic data is shown in Table 1 with no significant difference between the 2 groups in age (MannWhitney U test, $\mathrm{p}$-value: 0.559$)$, sex $\left(\mathrm{X}^{2}=0.282 ; \mathrm{df}=1\right.$, p-value: 0.596), pre-operative Haemoglobin levels (Mann-Whitney U test, $\mathrm{p}$-value $=0.819$ ), presence of hypertensive heart disease, diabetes mellitus and immunosuppressive states like HIV/AIDS or chronic drug abuse/steroid use. None of the patients in both groups had a history of smoking. The average injury-surgery interval was 8 days in each group for fresh fractures, and 20 months for mal- and non unions. Table 2 shows that femoral fractures were the commonest indication for surgery accounting for 27 presentations $(43.55 \%)$, followed by humeral fractures $(7 ; 11 \%-29 \%)$ and tibial fractures $(6 ; 9.66 \%)$. Plate and screw osteosynthesis was 
Table 1. Demographic data.

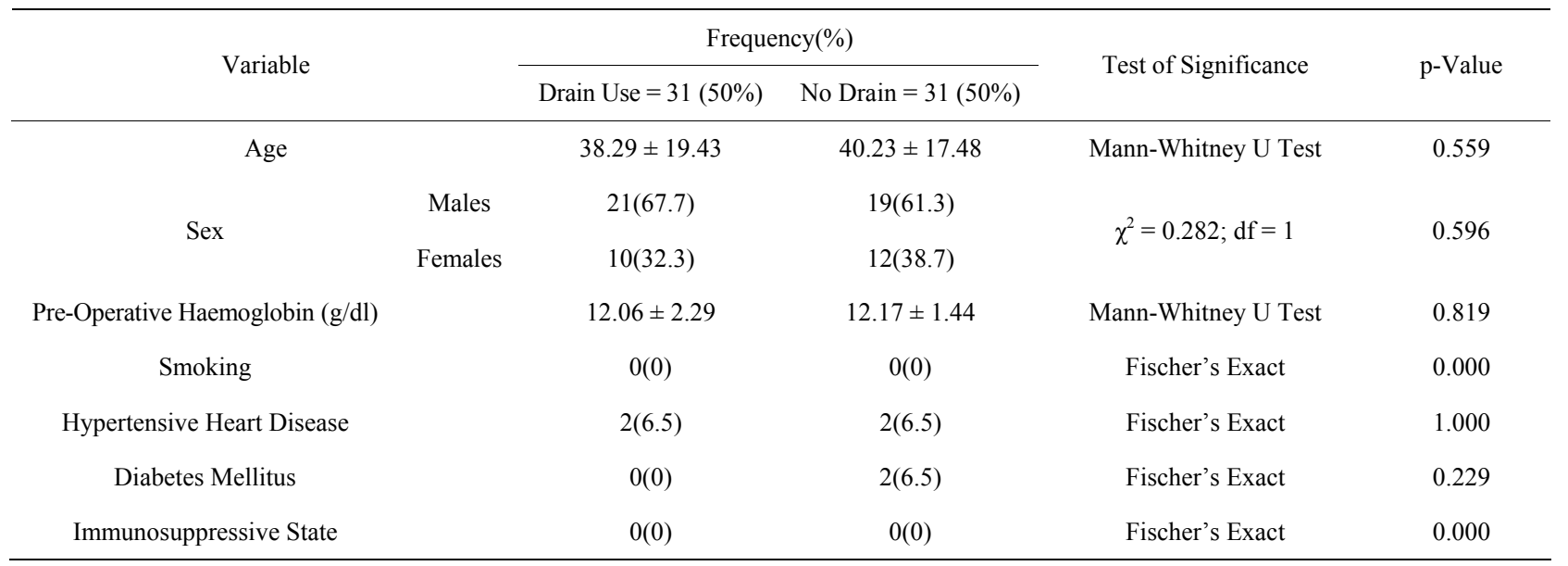

the most commonly performed procedure accounting for 15 cases (48.4\%) in the drain group and $21(67.7 \%)$ in the no drain group. Open interlocked intramedullary nailing accounted for 11 cases $(35.5 \%)$ in the drain group and 6 cases $(19.4 \%)$ in the no drain group. There were 5 hip arthroplasties with $1(3.2 \%)$ in the drain group and $4(12.9 \%)$ in the no drain group (Table 3).

In terms of the parameters evaluated, there were no incidents of compartment syndrome in both groups and no statistically significant difference in the pain scores at 6 and 12 hours post-operation. Considering orthopaedic wound severity, only closed fractures were included in the study and surgery was delayed in the presence of severe swelling of the affected site. The outcomes show that although statistically insignificant, there were 4 cases $(12.8 \%)$ of superficial early wound infection in the drain group and only 1 case $(3.2 \%)$ in the no drain group. There were equal numbers of wound swelling $(3 ; 9.7 \%)$ in each group. Transfusion requirements and number of units transfused post-operatively were higher in the drain group and this was statistically significant (Table 4). In the assessment of perfusion, capillary refill time was significantly prolonged in the drain group $(2.39 \pm 0.56 \mathrm{sec}-$ onds) compared to the non-drain group (2.03 $\pm 41 \mathrm{sec}-$ onds; p-value 0.007).

\section{Discussion}

The debate over prophylactic wound drainage transcends orthopaedic surgery. Lawson Tait's "when in doubt, drain" was countered by Halsted (1898) who argued that "no drainage at all is better than the ignorant employment of it" $[11,12]$. Closed suction drains are commonly used in orthopaedic surgery to avoid the accumulation of postoperative haematomas/seromas [6]. Haematomas can potentially increase tissue tension and therefore decrease tissue perfusion in the peri-wound area. This could have a detrimental effect on the wound with an increased risk of wound dehiscence and infection, and poor wound healing. The routine use of closed suction drains in orthopaedics has been controversial but the practice has endured despite the availability of studies that challenge

Table 2. Indications for surgery.

\begin{tabular}{ccc}
\hline Indication & $\begin{array}{c}\text { Drain Use } \\
\mathrm{n}=31 \mathrm{n}(\%)\end{array}$ & $\begin{array}{c}\text { No Drain } \\
\mathrm{n}=31 \mathrm{n}(\%)\end{array}$ \\
\hline Femoral Neck Fractures & $2(6.5)$ & $3(9.7)$ \\
Fracture Femoral Shaft & $17(54.8)$ & $10(32.3)$ \\
Fracture Humerus & $1(3.2)$ & $6(19.4)$ \\
Fracture Tibia & $3(9.7)$ & $3(9.7)$ \\
Fracture Radius/Ulna & $1(3.2)$ & $2(6.5)$ \\
Mal/Non Union Femur & $1(3.2)$ & $4(12.9)$ \\
Non Union Humerus & $2(6.5)$ & $2(6.5)$ \\
Osteoarthritis Hip & $-(0)$ & $1(3.2)$ \\
Others & $4(12.9)$ & $-(0)$ \\
& $31(100)$ & $31(100)$ \\
\hline
\end{tabular}

*Patella fracture, Ankle fracture, Genu varum, Genu valgum.

Table 3. Procedures performed.

\begin{tabular}{ccccc}
\hline & \multicolumn{2}{c}{ Drain Use $=31(50 \%)$} & No Drain $=31(50 \%)$ \\
\hline Procedure & Frequency & Percent & Frequency & Percent \\
\hline $\begin{array}{c}\text { Corrective } \\
\text { Osteotomy } \\
\text { Arthroplasty } \\
\text { (Hip) }\end{array}$ & 2 & 6.5 & 0 & 0 \\
$\begin{array}{c}\text { ORIF with } \\
\text { Interlocking Nail } \\
\text { ORIF with Plate } \\
\text { and Screws }\end{array}$ & 11 & 3.2 & 4 & 12.9 \\
$\begin{array}{c}\text { ORIF with Pins } \\
\text { and Wires }\end{array}$ & 15 & 48.4 & 21 & 67.7 \\
Total & 31 & 100 & 31 & 100 \\
\hline
\end{tabular}

$\mathrm{X}^{2}=10.20 ; \mathrm{df}=7 ; \mathrm{p}=0.177$. 
Table 4. Parameters evaluated and p-values.

\begin{tabular}{|c|c|c|c|c|}
\hline \multirow{2}{*}{ Variable } & \multicolumn{2}{|c|}{ Frequency(\%) } & \multirow{2}{*}{ Test of Significance } & \multirow{2}{*}{ p-Value } \\
\hline & Drain use $=31(50 \%)$ & No Drain $=31(50 \%)$ & & \\
\hline Pain Score at 6 Hours (Numeric Scale) & $2.26 \pm 0.69$ & $1.97 \pm 0.61$ & Mann-Whitney U Test & 0.113 \\
\hline Pain score at 12 hours (Numeric Scale) & $1.87 \pm 0.50$ & $1.65 \pm 0.49$ & Mann-Whitney U Test & 0.088 \\
\hline Wound Leakage & $2(6.5)$ & $0(0)$ & Fisher's Exact & 0.229 \\
\hline Wound Gape after Surgery & $3(9.7 \%)$ & $0(0)$ & Fisher's Exact & 0.107 \\
\hline Dressing Changes & $1(3.2)$ & $0(0)$ & Fisher's Exact & 0.483 \\
\hline Superficial Wound Infection & $4(12.8)$ & $1(3.2)$ & Fisher's Exact & 0.151 \\
\hline Swelling of Wound Edges & $3(9.7)$ & $3(9.7)$ & Fisher's Exact & 1.000 \\
\hline Post-Operative Blood Transfusion & $7(22.6)$ & $0(0)$ & Fisher's Exact & $0.009^{*}$ \\
\hline Capillary Refill Time (secs) & $2.39 \pm 0.56$ & $2.03 \pm 0.41$ & Mann-Whitney U Test & $0.007^{*}$ \\
\hline Post-Operative Haemoglobin & $9.90 \pm 2.38$ & $9.45 \pm 2.10$ & $\begin{array}{c}\text { T-Test } \\
0.762\end{array}$ & 0.45 \\
\hline Number of Units of Blood & $0.40 \pm 0.86$ & 0 & Mann-Whitney U Test & $0.005^{*}$ \\
\hline Number of Days to Suture Removal & $13.70 \pm 2.48$ & $12.90 \pm 2.12$ & Mann-Whitney U Test & 0.31 \\
\hline Interval between Surgery and Discharge & $15.83 \pm 4.61$ & $13.52 \pm 3.07$ & Mann-Whitney U Test & 0.63 \\
\hline
\end{tabular}

*Statistically significant.

it's efficacy and identify some potential drawbacks [3-8]. Western studies have noted the disparity between literature and common practice among orthopaedic surgeons [7-9].

African studies hardly exist. Yet the argument can be made that the absence of technologically advanced surgical armamentarium considered basic or routine in affluent societies such as diathermy and minimal access techniques is in strong support of prophylactic drainage of orthopaedic wounds in resource challenged settings. Meticulous attention to surgical technique remains an important tool in the prevention of haematomas and infection. Minimization of hematoma and seroma formation which potentially lowers the risk of infection and other wound complications, as well as reduction in the need for reinforcement or change of post-operative wound dressings are cited by proponents in support of surgical drainage $[11,13,14]$, while opponents cite studies suggestive of drains actually increasing the risk of infection $[15,16]$. Several studies exist that do not support the routine use of prophylactic drainage to reduce the frequency of post operative wound complications in orthopaedic surgery. Our results show no statistical differences between the drained and undrained groups with respect to pain scores, wound discharge, dressing change requirements and wound swelling. Prophylactic wound drainage therefore provides no clear advantages over a no-drainage policy with respect to these parameters.
There were 4 cases $(12.8 \%)$ of superficial wound infection in the drain group and one case $(3.2 \%)$ in the no drain group. The rate of post operative blood transfusion was significantly higher in the drain group $(p=0.009)$ and this agrees with other studies $[17,18]$. This outcome is particularly important because blood transfusion has documented risks including acquiring human immunodeficiency virus $(1: 500,000)$, Hepatitis B $(1: 63,000)$ and Hepatitis C (1 : 103,000), increased risk of death, myocardial infarction, stroke, renal failure and malignancy $[19,20]$; and increases treatment costs. Lowering the cost of treatment is an ongoing challenge in many health systems and is particularly important in resource challenged health systems [21].

In this study, we assessed tissue perfusion clinically by assessing the capillary refill time in the nail beds distal to the operation site. There was a statistically significant prolongation in the capillary refill times in the drain group $(2.39 \pm 0.56$ seconds) when compared to the no drain group $(2.03 \pm 0.41$ seconds; p-value 0.007$)$. This would suggest that wound perfusion is better in wounds with no drain when compared with prophylactically drained wounds. Further investigation may be required in this direction. There was no statistically significant difference between the number of days to suture removal and the surgery-discharge interval, and this agrees with other studies [17]. Wound leakage occurred in 2 patients in the drain group in our study and none in the no drain 
group. This differs from some reports which document leakage associated with not using a drain [19,22]. Other reports have however pointed out the need to determine whether wound leakage is "merely an inconvenience or associated with serious morbidity" [17].

The controversy associated with prophylactic wound drainage extends beyond the use or non-use of the device to the effect of drain pressure in Orthopaedic wound outcomes [23]. Our results agree with other studies from the developing world which show higher superficial surgical site infection rates associated with the use of drains and no significant changes in pain perception whether drains are used or not [24,25]. The routine use of drains in Orthopaedic procedures should be reconsidered [26,27] because non use of drains potentially decreases blood loss and transfusion requirements. In a resource challenged setting, the cost increases occasioned by transfusion needs and costs of drain device outweigh any advantages wound drainage may presumably confer. A sample size of 62 patients may be considered to be a limitation in this study. This can be explained in terms of the duration of study, a preference of the patients in our environment for traditional bone setting and institutional challenges that create competition for theatre space amongst different surgical specialties. However, like in other studies, our conclusion supports a re-think of prophylactic wound drainage in orthopaedics because it confers no obvious advantages.

\section{Conclusion}

Surgical wound drainage is a well established procedure but the complications are well documented [28], and the controversy surrounding the use of drains in orthopaedic surgery continues. While many surgeons may continue the "routine" practice of prophylactic wound drainage, there is a mounting body of evidence that the use of drains confer no advantages over their non-use in clean orthopaedic wounds [27]. This study, from a resource challenged region supports the proponents of no drainage. This will translate to reduced treatment costs which will benefit health systems in our region.

\section{REFERENCES}

[1] R. J. Gaines, "The Use of Surgical Drains in Orthopaedics," Orthopaedics, Vol. 3, No. 31, 2008, pp. 702-705. doi:10.3928/01477447-20110505-06

[2] J. P. Moss, "Historical and Current Perspectives on Surgical Drainage," Surgery, Gynecology, and Obstetrics, Vol. 152, No. 4, 1981, pp. 517-527.

[3] P. S. Barie, "Are We Draining the Life from Our Patients?" Surgical Infections, Vol. 3, No. 3, 2002, pp. 159160. doi:10.1089/109629602761624162

[4] R. Clifton, S. Haleem, A. Mckee and M. J. Parker, "Clos- ed Suction Surgical Wound Drainage after Hip Fracture Surgery; a Systematic Review and Meta-Analysis of Randomized Controlled Trials," International Orthopaedics (SICOT), Vol. 32, No. 6, 2008, pp. 723-727. doi:10.1007/s00264-007-0420-Z

[5] Q. D. Zhang, W. S. Guo, Q. Zhang, Z. H. Liu, L. M. Cheng and Z. R. Li, "Comparison between Closed Suction Drainage and Non-Drainage in Total Knee Arthoplastry: A Meta-Analysis," Journal of Arthroplasty, Vol. 26, No. 8, 2011, pp. 1265-1272.

[6] G. Tucci, V. Amorese and E. Romanini, "Closed Suction Drainage after Orthopaedic Surgery: Evidence versus Practice," Journal of Orthopaedics and Traumatology, Vol. 7, No. 1, 2006, pp. 29-32. doi:10.1007/s10195-006-0118-9

[7] A. Chandratreya, K. Giannikas and P. Livesky, "To Drain or Not to Drain; Literature versus Practice," Journal of the Royal College of Surgeons of Edinburgh, Vol. 43, No. 6, 1998, pp. 404-406.

[8] T. R. Waugh and F. E. Stinchfield, "Suction Drainage of Orthopaedic Wounds," Journal of Bone and Joint Surgery (American), Vol. 43A, No. 7, 1961, pp. 939-946.

[9] G. W. Varley and S. A. Milner, "Wound Drains in Proximal Femoral Fracture Surgery: A Randomized Prospective Trial of 177 Patients," Journal of the Royal College of Surgeons of Edinburgh, Vol. 40, No. 6, 1995, pp. 416418.

[10] M. J. Parker, V. Livingstone, R. Clifton and A. Mckee, "Closed Suction Surgical Wound Drainage after Orthopaedic Surgery," Cochrane Database of Systemic Reviews, No. 3, 2007, Article ID: CD001825.

[11] A. Loh and P. A. Jones, "Evisceration and Other Complications of Abdominal Drains," Postgraduate Medical Journal, Vol. 67, No. 789, 1991, pp. 687-688. doi:10.1136/pgmj.67.789.687

[12] R. R. Durai, A. A. Mownah and P. C. H. Ng, "Use of Drains in Surgery: A Review," Journal of Perioperative Practice, Vol. 19, No. 6, 2009, pp 180-186.

[13] S. G. Smith and M. S. Shapiro, "The Use of Drains for Outpatient Orthopaedic Surgeries: Safety and Efficacy," Ambulatory Surgery, Vol. 5, No. 4, 1997, pp. 145-147. doi:10.1016/S0966-6532(97)00042-5

[14] G. P. Khanal, R. Rijal, B. P. Shresthra, N. K. Karn and P. Chaudhary, "A Study to Evaluate the Role of Suction Drains in Orthopaedic Surgery," Health Renaissance, Vol. 9, No. 2, 2011, pp. 91-94. doi:10.3126/hren.v9i2.4980

[15] J. Walker, "Patient Preparation for Safe Removal of Surgical Drains," Nursing Standard, Vol. 21, No. 49, 2007 , pp. 39-41.

[16] M. A. Ritter, E. M. Keating and P. M. Faris, "Closed Wound Drainage in Total Hip or Total Knee Replacement," Journal of Bone and Joint Surgery (American), Vol. 76, No. 1, 1994, pp. 35-38.

[17] P. J. Walmsley, M. B. Kelly, R. M. F. Hill and I. B. Renkel, "A Prospective, Randomized, Controlled Trial of the Use of Drains in Total Hip Arthroplady," Journal of Bone and Joint Surgery (British), Vol. 87B, No. 10, 2005, pp. 1397-1401. doi:10.1302/0301-620X.87B10.16221 
[18] T.-W. Tai, C.-Y. Yang and C.-W. Chang, "The Role of Drainage after Total Knee Arthroplastry," In: S. Forkter, Ed., Recent Advances in Hip and Knee Arthroplastry, In Tech, Shanghai, 2012, pp. 267-274. doi:10.5772/26519

[19] J. J. Callaghan, "Patient Specific Transfusion Options in Total Hip and Knee Surgery," Orthopaedics, Vol. 23, No. 9, 2000, pp. 925-926.

[20] R. H. G. P. Van Erve and A. C. Wiekenkamp, "Transfusion Reduction in Orthopaedic Surgery," In: P. Kochnar Ed., Blood Transfusion in Clinical Practice, In Tech, Shanghai, 2012, pp. 61-82. doi:10.5772/33920

[21] D. Ovadia, E. Luger, J. Bickels, A. Menachem and S. Dekel, "Efficacy of Closed Wound Drainage after Total Joint Arthroplasty: A Prospective Randomized Study," Journal of Arthroplasty, Vol. 12, No. 3, 1997, pp. 317321. doi:10.1016/S0883-5403(97)90029-2

[22] J. A. Razzak and A. L. Kellermann, "Emergency Medical Care in Developing Countries: Is It Worthwhile?" Bulletin of the World Health Organization, Vol. 80, No. 11, 2002, pp. 900-905.

[23] Y. H. Kim, S. H. Cho and R. S. Kim, "Drainage versus Non-Drainage in Simultaneous Bilateral Total Hip Ar- throplasties," Journal of Arthroplasty, Vol. 13, No. 2, 1998, pp. 156-161. doi:10.1016/S0883-5403(98)90093-6

[24] K. W. Cheung and K. H. Chiu, "Effect of Drain Pressure in Total Knee Arthroplasty," Journal of Orthopaedic Surgery, Vol. 14, No. 2, 2006, pp. 163-166.

[25] A. Karbalaeikhani and A. Saied, "Postoperative Drains at the Donor Sites of Iliac-Crest Bone Grafts in Patients Who Had a Single Comminuted Long Bone fracture," Surgical Science, Vol. 2, No. 9, 2011, pp. 437-441.

[26] T. W. Tai, I. M. Jou, C. W. Chang, K. A. Lai, C. J. Jin and C. Y. Yang, "Non-Drainage Is Better than 4-Hour Clamping Drainage in Total Knee Arthroplasty," Orthopaedics, Vol. 33, No. 3, 2010, pp. 156-160.

[27] C. Li, A. Nijat and M. Askar, "No Clear Advantage to Use of Wound Drains after Unilateral Total Knee Arthroplasty," The Journal of Arthroplasty, Vol. 26, No. 4, 2011, pp. 519-522.

[28] K. Panonsis, P. Grigoris and A. E. Strover, "Suction DressIngs in Total Knee Arthroplasty-An Alternative to Deep Suction Drainage," Acta Orthopaedica Belgica, Vol. 70, No. 4, 2004, pp. 349-354. 